\title{
Geographic Patterns and Stand Variables Influencing Growth and Vigor of Populus tremuloides in the Sierra Nevada (USA)
}

\author{
John-Pascal Berrill and Christa M. Dagley \\ Department of Forestry and Wildland Resources, Humboldt State University, 1 Harpst Street, Arcata, CA 95521, USA \\ Correspondence should be addressed to John-Pascal Berrill, pberrill@humboldt.edu
}

Received 2 October 2012; Accepted 20 October 2012

Academic Editors: G. Martinez Pastur and H. Zeng

Copyright ( $) 2012$ J.-P. Berrill and C. M. Dagley. This is an open access article distributed under the Creative Commons Attribution License, which permits unrestricted use, distribution, and reproduction in any medium, provided the original work is properly cited.

\begin{abstract}
Awareness of geographic patterns and stand variables that influence tree growth will help forest managers plan appropriate management and monitoring strategies. We quantified influences of stand location, species composition, stand density, and tree size on aspen tree growth and vigor around the Lake Tahoe Basin in the Sierra Nevada Mountains of California and Nevada, USA. Radial growth data were taken from increment cores. Aspen trees on the south and west sides of the lake grew 20-25\% faster than aspen in north and east side stands. Diameter growth at 2,400 m elevation was 58\% of growth at 1,900 m near lake level. Aspen grew faster with less competition from neighbor trees. At any level of competition, aspen growth was slower beside conifer neighbors and correlated with crown ratio (CR: length of live crown relative to total tree height, a proxy for tree vigor). Analysis of independent CR data for 707 aspen trees in nine additional stands indicated that aspen had smaller crowns in the presence of greater competition, and that composition of neighbor trees also affected CR: aspen trees had shorter crowns in the presence of conifer at higher stand densities. Taken collectively, our analyses point towards a cascading decline in aspen growth and vigor incited by succession of aspen stands to conifers. Our findings suggest that conifer removal and stand density control in aspen-conifer stands at Lake Tahoe will enhance aspen growth and vigor.
\end{abstract}

\section{Introduction}

Quaking aspen (Populus tremuloides Michx.) communities are being replaced by conifers throughout many forests and rangelands of North America [1-9]. Succession to coniferous species is expected in the absence of disturbances such as wildfires that kill young conifers establishing within aspen stands [10]. Pioneering features such as lightweight seed, shade intolerance, and rapid growth of vegetative root-sucker regeneration indicate that aspen is adapted to disturbance $[10,11]$. Having the widest distribution of any native tree in North America suggests that aspen has benefitted from a long history of natural disturbances. Fire suppression throughout much of the 20th Century has lengthened fire return intervals, allowing conifers time to establish and develop thicker fire-resistant bark with advancing size and age. Conifers eventually overtop aspen and suppress aspen regeneration and herbaceous vegetation.

Loss of aspen forest area merits concern because aspen is considered a keystone species $[12,13]$, and aspen is the foundation species in stands that are "hotspots" of biodiversity [14]. At the western edge of aspen's natural range, in the Sierra Nevada Mountains of California and Nevada, aspen stands are ranked higher in biodiversity than meadows and conifer stands [15]. Pure aspen stands support a diverse herbaceous understory and a greater abundance of bird species than mixed stands where aspen is intermingled with conifers [16]. Large, widely spaced old aspen stems often have cavities used by nesting birds, and also have aesthetic value, especially when they support patches of rust-colored lichen. Arborglyphs carved on aspen stems by Basque shepherds in the 1800s impart cultural value. In the vicinity of Lake Tahoe, in the central Sierra Nevada, aspen are mostly restricted to moister riparian areas where they stabilize banks of streams flowing into Lake Tahoe.

Lake Tahoe covers $490 \mathrm{~km}^{2}$ within a $1,310 \mathrm{~km}^{2}$ watershed referred to as the Lake Tahoe Basin where most aspen exist in isolated patches within a matrix of coniferous forest. These isolated clones generally have young conifers establishing beneath the canopy. In some stands, a majority of aspen 
stems have died, fallen, and almost completely been replaced by conifers. Many aspen stands around Lake Tahoe appear to have poor recruitment of aspen regeneration to sapling and pole stages. It is unclear whether these stands are "decadent" [17], whether crowding is preventing recruitment to the main canopy, or if the existing stems are healthy and do not need replacement. At Rocky Mountain National Park, Kaye et al. [6] reported episodic "pulses" of aspen regeneration, giving rise to distinct cohorts of stems within stands, followed by periods of low regeneration. At the landscape level, Binkley [18] found all ages represented in aspen stands throughout Rocky Mountain National Park, with regeneration arising at different times after different types of disturbances at different locations. The age structure of aspen stands surrounding Lake Tahoe is unknown. Also unknown is whether aspen at Lake Tahoe are usually pioneers that temporarily colonized newly disturbed areas, or whether aspen exist here as stable, persistent clones. The presence of a few very large, old conifers in some aspen stands suggests that pure aspen stands rarely exist in a stable condition; rather, that longer fire return intervals over the 20th Century created an imbalance favoring conifer in mixed aspen-conifer stands. With fewer disturbances there are also fewer opportunities for colonization of newly disturbed areas by aspen seed, while the dense conifer forest matrix may provide obstacles to sexual reproduction among the isolated dioecious aspen clones [13]. Therefore, if land managers want to maintain an aspen component within the conifer-dominated forests of the Lake Tahoe Basin, the existing stands will likely need to be regenerated in situ or thinned to relieve crowding. Removal of smaller conifers from aspen stands is being undertaken throughout the Lake Tahoe Basin. Response to conifer removal is being monitored, but without any knowledge of expected growth rates at different locations or elevations. Thus, there is no benchmark against which to compare posttreatment aspen tree growth.

Tree growth rate estimates inform the design of treatments that promote rapid development of large aspen stems, and prediction of "treatment persistence," the time taken for a stand to return to pretreatment condition or an undesirable state of crowding. Tree growth rates can be predicted with the Forest Vegetation Simulator (FVS; [19]) using local coefficients from the Western Sierra Nevada Variant [20]. Speciesspecific coefficients are available for Sierra Nevada conifers. However, aspen is currently assigned the same coefficients as several other hardwoods found in the Sierra Nevada foothills and above, suggesting that predictions of aspen diameter growth throughout the Lake Tahoe Basin may not be reliable or sensitive to local conditions. In the absence of repeated measures data from permanent plots, retrospective growth analysis of data from destructive sampling, or increment cores can provide indicative estimates of growth. Aspen diameter growth data have successfully been obtained from tree ring-width measurements taken from increment cores $[1,21,22]$. In the absence of disturbance history and mortality data, such analyses are usually restricted to recent growth, because we have more confidence relating the width of outer rings to the present stand structure and tree variables such as live crown ratio (a proxy for tree vigor).
The objective of this study was to examine patterns of recent diameter growth in aspen stands growing around the Lake Tahoe Basin and covering a "matrix" of possible stand conditions and tree sizes for regression analysis of aspen tree growth. We hypothesized that aspen tree growth (i) differed between geographic locations and elevations, (ii) correlated with tree and crown size, and (iii) decreased at higher stand densities and in the presence of conifers. The importance of crown ratio (CR) as a predictor of diameter growth prompted an analysis of factors which were hypothesized to be negatively correlated with aspen tree vigor in terms of CR: tree size, stand density, and species composition in terms of percent conifer.

\section{Methods}

2.1. Study Area. Climate in the Lake Tahoe Basin (lat. $39^{\circ} 05^{\prime} \mathrm{N}$, long. $120^{\circ} 02^{\prime} \mathrm{W}$ ) is Mediterranean continental with cold winters and summers that feature cool nights and warm days with low humidity. Near lake level, at the Lake Tahoe Airport (elevation 1,906 m), August is normally the warmest month with an average maximum of $25.9^{\circ} \mathrm{C}$ and an average minimum of $4.3^{\circ} \mathrm{C}$. January is the coolest month with an average maximum of $5.0^{\circ} \mathrm{C}$ and an average minimum of $-9.4^{\circ} \mathrm{C}$. Minimum temperatures of $0^{\circ} \mathrm{C}$ or lower occur on an average of 231.8 days annually. Mean annual precipitation varies between years, on average ranging from $660 \mathrm{~mm}$ near the lake on the east side of the basin to over $1440 \mathrm{~mm}$ on the west side of the basin. Most precipitation falls as snow between November and April (http://www.wrcc.dri.edu/). At higher elevations, the snowpack persists longer in spring and aspen leaf emergence begins later; however, the relationship between elevation and average annual growth of aspen is unknown.

2.2. Retrospective Growth Data and Analysis. Twenty aspen stands were selected for sampling on the basis of differences in elevation and location around the Lake Tahoe Basin, and absence of major recent disturbance. At each site we measured recent diameter growth of 10 aspen stems covering a range of tree sizes across a range of stand densities in patches of pure aspen and aspen-conifer mixtures within each sample stand. Selected aspen stems were measured for $\mathrm{dbh}$, tree height, and live crown base height. Canopy stratum and crown class were recorded. One breast height increment core was collected from the uphill side of stems $<20 \mathrm{~cm} \mathrm{dbh}$; two cores 90 degrees apart (uphill, cross hill) were collected from stems $>20 \mathrm{~cm}$ dbh. Bark thickness was measured on each core sample. An estimate of stand density (in terms of basal area) and species composition in the vicinity of each sample aspen was obtained by separately tallying aspen, conifer, and hardwood stems within the critical radius of a $9.18 \mathrm{~m}^{2} \mathrm{ha}^{-1}$ basal area factor variable radius plot centered on the aspen stem being cored. Conifer tallies were separated into groups for pine, fir, and juniper; specifically, lodgepole and Jeffrey pine (Pinus contorta Douglas ex Loudon var. murrayana (Balf.) Engelm.; P. jeffreyi Grev. and Balf.), white and red fir (Abies concolor (Gord. and Glend.) Lindl. 
ex Hildebr.; Abies magnifica A. Murr.), and Sierra juniper (Juniperus occidentalis ssp. australis). The hardwood group included mountain alder (Alnus incana ssp. tenuifolia) and various willows (Salix spp.). Combining prism plot tallies for all species groups gave an estimate of stand density, termed "vicinity basal area" (BA), which included BA of the sample aspen stem at plot center. Species composition in the vicinity of each sample aspen was calculated as the proportion of BA in either: aspen, conifer, or other hardwoods. Each site was categorized by its location with respect to Lake Tahoe (north, south, east, or west side of the lake). Sample stand elevation was recorded with a handheld GPS.

Increment cores were measured for radial growth over the most recent full five years of growth $(2006,2007, \ldots .2010$ growing seasons). Measurements were taken to the nearest $0.01 \mathrm{~mm}$ using digital calipers under magnification. The average radial growth for each stem was converted to an average annual BA increment (BAI) assuming zero bark growth over the last five years. Using only five growth rings was a compromise between using more rings to better account for interannual variations versus using only the most recent rings that were more likely to reflect growth within the existing stand structure (that we sampled for BA) and not a former structure altered by a disturbance during the growth measurement period.

We constructed generalized linear mixed models to examine relationships between aspen BAI, the dependent variable, and candidate explanatory variables: tree size ( $\mathrm{dbh}$ ), canopy position, vicinity BA and composition (conifer $\mathrm{BA} \%)$, and stand location and elevation. Models were fitted using PROC GLIMMIX in SAS [23, 24]. The nesting of aspen sample trees within different stands (assuming each stand comprised one aspen clone) was accounted for by specifying "stand" as a random effect in the mixed model. Selection of variables for inclusion in the final model was based on likelihood ratio tests comparing the full model against reduced models in terms of model chi square. Vicinity BA replaced crown class in the final model to avoid confounding due to the correlation between these variables. To check for problems caused by multicollinearity between explanatory variables, we (i) calculated variance inflation factors (VIFs) from coefficients of determination obtained by regressing each continuous explanatory variable against all others; (ii) removed each variable sequentially and refitted the generalized linear mixed model with all other variables which allowed us to check for stability in the sign and magnitude of estimates for each fixed effect.

The final model was used to obtain estimates of the "average" (expected) growth rate for aspen across the entire range of sites and conditions sampled. By holding constant the model inputs, the effect of each factor influencing aspen BA increment was examined separately. For example, by fixing tree size, elevation, and species composition and varying stand BA, we isolated the impact of competition in terms of stand BA. Similarly, by holding stand BA constant and varying species composition, we obtained model predictions that demonstrated the impact of increasing conifer presence on aspen growth; separated from the contribution of conifers to stand density in terms of BA. In essence, these were two separate corollaries between conifer composition and reduced aspen growth: competition (regardless of species) and conifer competition (relatively more conifer at any level of competition).

2.3. Crown Ratio Data and Analysis. Crown ratio data were collected in nine aspen-conifer stands around the Lake Tahoe Basin. Three stands were located on the western side of the lake, three on the southern side, and three on the eastern side. A 1-ha plot was established in each sample stand, and each tree $>10 \mathrm{~cm}$ dbh was measured for $\mathrm{dbh}$, height, and live crown base height. Subtracting live crown base height from total tree height gave crown length. Dividing crown length by tree height gave aspen CR. Instances of damage or health problems that might affect CR were recorded. A series of survey points was established throughout each 1-ha plot and tree locations were mapped using a tripod-mounted flux gate compass to obtain azimuth and sonar hypsometer for distance from the nearest survey point to each tree.

We created a stem location map for each 1-ha plot by converting tree location data from distance and azimuth to an easting $(x)$ and northing $(y)$ for each stem. We queried each stem location map to estimate the amount of competition around each aspen stem, and the species composition of neighboring stems, using ArcGIS. A buffer of $7.98 \mathrm{~m}$ radius was created around each aspen stem $>10 \mathrm{~cm} \mathrm{dbh}$, giving a 0.02-ha subplot centered on each stem. Subplots that intersected with the 1-ha plot boundary shapefile were discarded. Tree data from each subplot were summarized, giving BA per hectare and stand density index for the aspen and conifer stand components, and other hardwoods when present. Stand density index (SDI) was calculated by summing individual tree SDI because the dbh data were not normally distributed: SDI $=\sum\left(0.04 \mathrm{dbh}_{i}\right)^{a}$ where $\mathrm{dbh}_{i}=$ $\mathrm{dbh}$ in $\mathrm{cm}$ of the $i$ th tree in the subplot, and $a=1.605$ $[25,26]$. Species composition in each subplot was calculated as the proportion of aspen and proportion of conifer in terms of BA. The resulting proportions were arcsine transformed.

The impact of various types of tree damage and health problems on aspen CR was quantified by multiple linear regression dummy variable analyses using PROC REG in SAS [23]. Among all aspen trees in the nine 1-ha plots, incidences of damage and health problems were grouped to create dummy variables for "sickly"/dying trees (very sparse foliage); trees with dead tops; broken tops and forking; extreme lean ( $>30$ degrees); stem damage/decay (conk, canker, scars, and cavities). Data for trees with damage that significantly affected CR were excluded from subsequent analyses. Aspen tree size data and the summary data (stand density, composition) for the subplot centered on each aspen stem were transformed to reduce skewness in frequency distributions. Generalized linear mixed models described relationships between arcsine-transformed CR data for each aspen stem and subplot data. Models were fitted using PROC GLIMMIX in SAS $[23,24]$. Aspen tree size (dbh) and neighbor tree summary data $\left(\mathrm{SDI}_{\text {aspen }}, \mathrm{SDI}_{\text {conifer }}, \mathrm{SDI}_{\text {total }}\right.$, and percent conifer composition) entered candidate models as fixed effects. At the stand level, the product of conifer composition and SDI for the entire 1-ha plot gave an overall 
"stand-level succession index." The influence of conifer competition at the stand level on tree CR was examined by incorporating the succession index as a fixed effect in the mixed model of CR. The class variable "site" entered the models as a random effect to account for nesting of aspen stems (presumably belonging to the same clone) at each study site. Model selection was based on likelihood ratio tests comparing the full model against reduced models in terms of model chi square at the 0.05 significance level.

\section{Results}

3.1. Diameter Growth. Aspen growth was sampled across a wide gradient of "local neighborhood competition" assessed in terms of vicinity BA (Table 1). Composition of neighbor trees ranged from pure aspen to pure conifer; hardwoods other than aspen were present in a few instances. On average, fir trees were more common than pine trees in the vicinity of aspen trees. When BA of the sample aspen tree was included in calculations of species composition, the maximum percent conifer was $89 \%$. Aspen trees sampled for growth had a broad range of sizes, crown ratios, and growth rates. The five-year average annual tree BA increment (BAI) was 25\% lower at sites on the north and east sides of the Lake Tahoe Basin (Table 2). Age data collected from a subset of the increment cores were highly variable and showed that sample stands were multiaged. The largest three aspen trees in our sample had breast-height ages of 151, 148, and 134 years, indicating that these stands had developed in the absence of a stand replacing disturbance since at least the mid-to-late 1800s.

Our mixed-effects model analysis of aspen tree BA growth indicated that radial growth differed significantly between locations and according to elevation, tree size, crown ratio, and neighbor tree competition and composition. Basal area growth did not differ significantly between the south and west sides of the Lake Tahoe Basin, and between the north and east sides; data for these locations were pooled. Growth was faster, on average, among aspen at southern and western locations, yet variability between trees and the low degrees of freedom (denominator $\mathrm{df}=$ 1) between south/west and north/east locations prevented detection of statistically significant differences between locations $(P=0.20)$ despite the high $t$-value $(-3.07)$ and the large $F$ value in the type III test of fixed effects (9.41). However, location was retained as a categorical variable in the final model, because it gave a significant improvement in model fit in terms of log likelihood. The quadratic tree dbh parameter was highly significant $(P<0.0001)$ indicating that BA growth accelerated, peaked, and then declined with advancing tree size and age. Slower BA growth among larger trees at higher elevations was modeled by the negative $\mathrm{dbh} \times$ elevation interaction. Aspen trees with higher CRs grew faster. Radial growth was significantly impacted by neighbor tree competition in terms of vicinity BA. The composition of neighbor trees also affected growth; aspen with other aspen trees as neighbors grew faster than aspen with equivalent vicinity BA composed of conifer (Table 3 ). Multicollinearity between explanatory variables was not considered problematic, because VIFs were low $(<1.36)$ and
TABLE 1: Summary data for variable radius plots centered on sample aspen trees $(n=175)$ giving vicinity basal area (BA) including BA of sample aspen tree, and composition of neighbor trees (in terms of percent BA; excluding sample aspen tree) in 20 stands around Lake Tahoe Basin.

\begin{tabular}{lcccc}
\hline Variable & Mean & s.d. & Min. & Max. \\
\hline Vicinity BA $\left(\mathrm{m}^{2} \mathrm{ha}^{-1}\right)$ & 49.2 & 20.5 & 18.4 & 119.4 \\
Aspen (\%) & 56.3 & 41.3 & 0.0 & 100.0 \\
Conifer (\%) & 31.7 & 37.8 & 0.0 & 100.0 \\
$\quad$ Pine spp. (\%) & 13.4 & 27.3 & 0.0 & 100.0 \\
$\quad$ Fir spp. (\%) & 17.8 & 30.1 & 0.0 & 100.0 \\
Hardwood (\%) & 1.1 & 8.5 & 0.0 & 100.0 \\
\hline
\end{tabular}

TABLe 2: Sample stand elevation and aspen tree size and growth summary data for stands located on northern and eastern $(n=86)$ or southern and western $(n=89)$ sides of the Lake Tahoe Basin. Growth was average annual increment over most recent five years for diameter (DBHI) and stem basal area (BAI).

\begin{tabular}{lccccc}
\hline Location & Variable & Mean & s.d. & Min. & Max. \\
\hline \multirow{5}{*}{ North and east } & Elevation $(\mathrm{km})$ & 2.22 & 0.14 & 1.90 & 2.42 \\
& Dbh $(\mathrm{cm})$ & 20.39 & 9.81 & 6.80 & 47.70 \\
& Height $(\mathrm{m})$ & 13.57 & 4.64 & 5.50 & 26.00 \\
& Crown ratio & 0.59 & 0.14 & 0.18 & 0.84 \\
& DBHI $\left(\mathrm{cm} \mathrm{year}^{-1}\right)$ & 0.25 & 0.13 & 0.05 & 0.66 \\
& BAI $\left(\mathrm{cm}^{2}\right.$ year $\left.^{-1}\right)$ & 7.41 & 4.50 & 1.16 & 20.42 \\
\hline \multirow{5}{*}{ South and west } & Elevation $\left(\mathrm{km}^{\prime}\right)$ & 2.14 & 0.19 & 1.91 & 2.38 \\
& Dbh $(\mathrm{cm})$ & 19.60 & 10.64 & 6.00 & 55.50 \\
& Height $(\mathrm{m})$ & 14.01 & 5.10 & 5.40 & 26.50 \\
& Crown ratio & 0.62 & 0.13 & 0.28 & 0.87 \\
& DBHI $\left(\mathrm{cm} \mathrm{year}^{-1}\right)$ & 0.38 & 0.18 & 0.05 & 0.83 \\
& BAI $\left(\mathrm{cm}^{2}\right.$ year $\left.^{-1}\right)$ & 9.93 & 5.76 & 0.96 & 25.63 \\
\hline
\end{tabular}

estimates for the fixed effects remained stable as each variable exited and reentered the generalized linear mixed model.

Standardized coefficients for the fixed effects indicated that aspen tree size and the tree size-elevation interaction correlated most strongly with diameter growth, followed in order of importance by $\mathrm{CR}$, geographic location, conifer presence in terms of percent BA, and lastly neighbor competition in terms of BA (Table 3). Model predictions depicted the direction and magnitude of these effects across the range of sample tree sizes, elevation, competition, and CR. Aspen stands on the south and west side of the lake grew 20-25\% faster than north and east side stands. Growth at $2,400 \mathrm{~m}$ elevation was $58 \%$ of growth at $1,900 \mathrm{~m}$ near lake level. Aspen trees grew faster with less competition from neighbor trees. With composition held constant to show how competition affects growth, the expected BAI of a 30$\mathrm{cm}$ dbh aspen stem increased $17 \%$ when stand density was reduced from $100 \mathrm{~m}^{2} \mathrm{ha}^{-1}$ to $50 \mathrm{~m}^{2} \mathrm{ha}^{-1}$ BA. Alternatively, when competition was held constant and composition varied to reveal impacts of conifer presence, the expected BAI of a $30-\mathrm{cm} \mathrm{dbh}$ aspen in a pure stand was $15 \%$ greater than aspen 
TABLE 3: Generalized linear mixed model of aspen stem basal area increment (BAI; $\mathrm{cm}^{2}$ year ${ }^{-1}$ ) for $n=175$ aspen trees in 20 stands around Lake Tahoe Basin. -2 Log Likelihood $=299.6$. Dependent variable $=(\text { BAI }+1)^{0.5}$. Categorical variable for location: North/east, south/west. Elevation in $\mathrm{km}$. $E_{\mathrm{Std}}$ : Estimate for standardized coefficients of fixed effects.

\begin{tabular}{|c|c|c|c|c|c|c|c|}
\hline Effect & Parameter & Estimate & s.e. & $\mathrm{df}$ & $t$ & $\mathrm{pr}>t$ & $E_{\text {Std. }}$ \\
\hline \multirow{9}{*}{ Fixed } & Intercept & 0.16330 & 0.4114 & 18 & 0.40 & 0.6962 & 3.0 \\
\hline & North/east & -0.35740 & 0.1165 & 1 & -3.07 & 0.2006 & -2.4 \\
\hline & South/west & 0.00000 & - & - & - & - & - \\
\hline & $\operatorname{Dbh}(\mathrm{cm})$ & 0.34550 & 0.0608 & 149 & 5.68 & $<0.0001$ & 46.6 \\
\hline & $\mathrm{Dbh}^{2}$ & -0.00146 & 0.0003 & 149 & -4.89 & $<0.0001$ & -10.0 \\
\hline & Dbh $\times$ Elevation $^{0.5}$ & -0.14780 & 0.0412 & 19 & -3.59 & 0.0019 & -29.7 \\
\hline & Crown ratio ${ }^{\mathrm{a}}$ & 1.73780 & 0.3221 & 149 & 5.40 & $<0.0001$ & 3.4 \\
\hline & Vicinity BA $\left(\mathrm{m}^{2} \mathrm{ha}^{-1}\right)$ & -0.00493 & 0.0021 & 149 & -2.33 & 0.0214 & -1.3 \\
\hline & Percent conifer $\mathrm{BA}^{\mathrm{b}}$ & -0.30070 & 0.1014 & 149 & -2.97 & 0.0035 & -1.6 \\
\hline \multirow{2}{*}{ Random } & Stand $(n=20)$ & 0.03705 & 0.0222 & & & & \\
\hline & Residual & 0.23300 & 0.0269 & & & & \\
\hline
\end{tabular}

${ }^{a}$ Crown ratio (arcsine transformed) $=\operatorname{Sin}^{-1}\left(\mathrm{CR}^{0.5}\right)$.

${ }^{\mathrm{b}}$ Percent conifer BA (arcsine transformed $)=\operatorname{Sin}^{-1}\left((0.01 * \text { percent conifer BA })^{0.5}\right)$ where percent composition in terms of vicinity BA included BA of the sample aspen and all neighbor trees.

growing in mixture with $50 \%$ conifer, and all else remaining equal (Figure 1).

3.2. Crown Ratio. Aspen CR was significantly related to tree size (dbh), stand density (SDI), and species composition of neighbor trees (percent conifer BA), but varied widely between trees $\left(n=948 ; R^{2}\right.$ adj. $\left.=0.14\right)$. Thirty percent of sample trees had some form of damage (i.e., dead or broken top, forking, stem scar, cavity, or extreme lean) or health problem (i.e., conk, stem canker, or "sickly" appearance). The multiple linear regression with a dummy variable for incidence of damage or health problems indicated that, on average, damaged/unhealthy trees had CRs 0.053 lower than undamaged, healthy trees $(P<0.0001)$. Separate dummy variables for each category of tree damage and health problems improved multiple linear regression model fit $\left(R_{\text {adj. }}^{2}=0.20\right)$. Multiple linear regression coefficients indicated that, when compared to undamaged, healthy aspen of a given size and neighbor competition, CR was 0.138 lower among sickly/dying trees $(n=13 ; P=0.0006), 0.149$ lower among aspen with dead tops $(n=15 ; P<0.0001), 0.132$ lower among aspen with broken tops $(n=6 ; P=0.02)$, and 0.040 lower among the many aspen with some form of stem damage or decay $(n=225 ; P=0.0002)$. Crown ratio was lower among leaning trees $(-0.075 ; n=4, P=0.29)$, but this difference was not significant. There was no difference in CR between aspen with forked tops $(0.001 ; n=57 ; P=0.95)$ and undamaged, healthy trees. Therefore, data for healthy and undamaged aspen trees with and without forked tops were selected for analysis of the relationship between CR and tree size, stand density, and species composition (Table 4).

The best generalized linear mixed model fitted to CR data for 707 aspen (including healthy, undamaged, and forked trees) indicated that CR decreased as aspen trees grew larger. A logarithmic transformation of dbh improved model fit, indicating that $\mathrm{CR}$ initially decreased rapidly as tree $\mathrm{dbh}$ increased from $10 \mathrm{~cm}$ to $30 \mathrm{~cm}$, then became more stable
TABle 4: Summary data for aspen trees used for crown ratio analysis, and elevation of sample stands. Vicinity BA, SDI, and composition (in terms of percent conifer BA) of neighbor trees taken from 0.02 ha circular plot centered on each sample aspen $(n=707)$ within sample stands around Lake Tahoe Basin $(n=9)$.

\begin{tabular}{lcccc}
\hline Variable & Mean & s.d. & Min. & Max. \\
\hline Dbh $(\mathrm{cm})$ & 28.47 & 15.42 & 10.00 & 86.50 \\
Height $(\mathrm{m})$ & 18.16 & 7.07 & 5.30 & 34.90 \\
Crown height $(\mathrm{m})$ & 9.64 & 5.11 & 1.10 & 22.90 \\
Crown ratio & 0.48 & 0.15 & 0.15 & 0.89 \\
Vicinity BA $\left(\mathrm{m}^{2} \mathrm{ha}^{-1}\right)$ & 57.65 & 33.12 & 0.50 & 199.52 \\
Vicinity SDI & 985.98 & 509.61 & 15.00 & 2551.55 \\
Conifer $(\%$ by BA) & 43.23 & 32.08 & 0.00 & 99.44 \\
Elevation $(\mathrm{km})$ & 2.11 & 0.13 & 1.90 & 2.26 \\
\hline
\end{tabular}

as dbh increased beyond $30 \mathrm{~cm}$. Aspen CR was lower in the presence of greater competition. An interaction term indicated that the composition of neighbor trees also affected CR as stand density increased; aspen trees had shorter crowns in the presence of conifer at higher stand densities. Standardized coefficients for the fixed effects in the mixed model indicated that aspen CR correlated most strongly with stand density, followed in order of importance by tree size, and the interaction between SDI and composition of neighbor trees (Table 5). Predictions were generated for the range of stand densities in areas of pure aspen $($ SDI $<1600)$ and in areas where succession to conifer was occurring and higher stand densities were encountered (SDI < 2500). Results indicated that as stand density increased, aspen had shorter crowns; this loss of crown was exacerbated when neighbor trees were conifer, especially at higher stand densities. For example, CR for a $30-\mathrm{cm} \mathrm{dbh}$ aspen stem in a pure stand is expected to decrease $9 \%$ (from 0.54 to 0.49 ) as stand density increases from 500 to 1000 SDI. In a mixed stand 

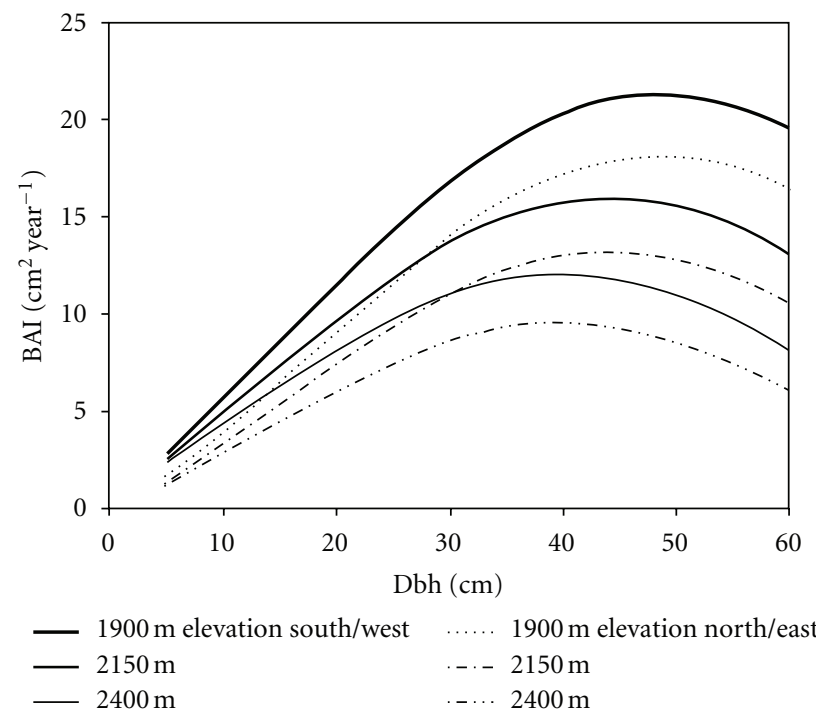

(a)
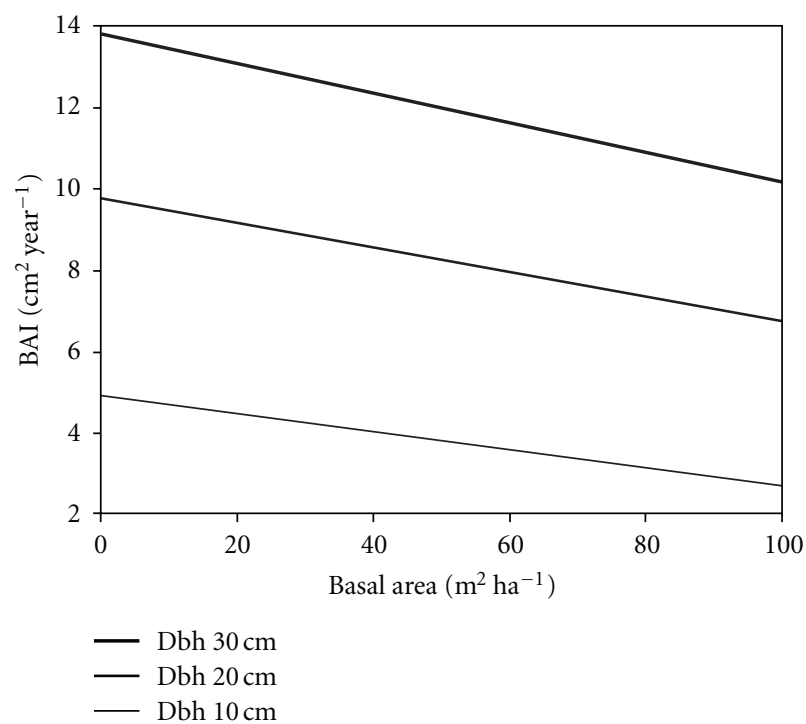

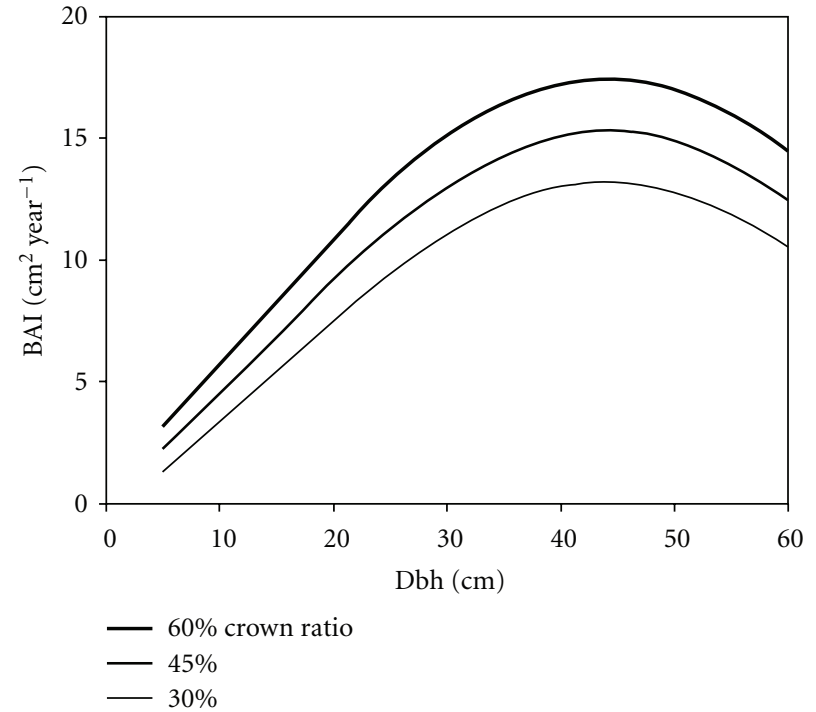

(b)

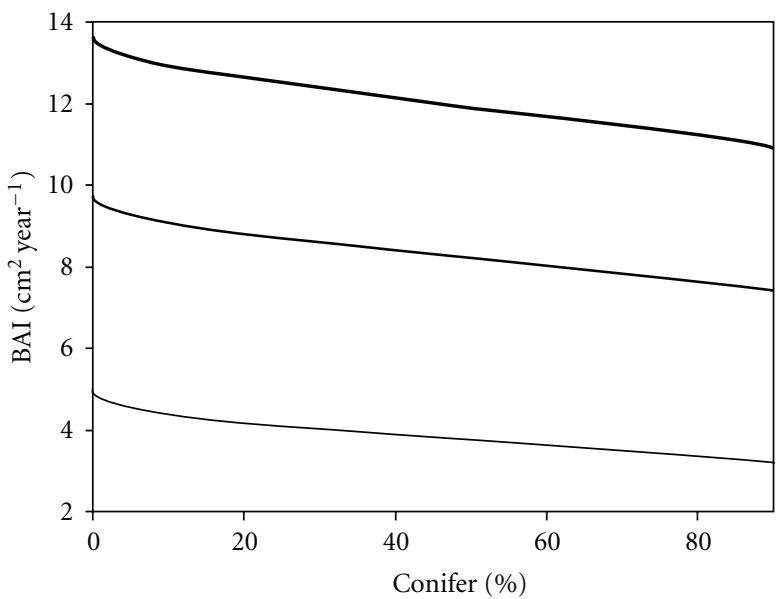

Dbh $30 \mathrm{~cm}$

Dbh $20 \mathrm{~cm}$

Dbh $10 \mathrm{~cm}$

(c)

(d)

FIGURE 1: Relationship between aspen basal area increment (BAI) and tree size (dbh), compared between locations around Lake Tahoe Basin (north/east and south/west sides of basin at low, medium, and high elevation) and according to aspen crown ratio for pure aspen stands at $50 \mathrm{~m}^{2} \mathrm{ha}^{-1} \mathrm{BA}((\mathrm{a})$ and (b)), and as a function of competition in terms of BA and conifer encroachment in terms of percent BA ((c) and (d)). Unless otherwise stated, BAI estimates obtained from generalized linear mixed model were based on crown ratio 0.5 , vicinity BA $50 \mathrm{~m}^{2}$ ha ${ }^{-1}$ composed of $50 \%$ conifer by BA, at 2,150 m elevation on the south/west side of Lake Tahoe Basin.

TABLE 5: Generalized linear mixed model of aspen crown ratio (CR) for $n=707$ aspen trees in 9 stands around Lake Tahoe Basin. -2 Log Likelihood $=879.0$. Dependent variable $=\operatorname{Sin}^{-1}\left(\mathrm{CR}^{0.5}\right) . E_{\text {Std. }}$ : Estimate for standardized coefficients of fixed effects.

\begin{tabular}{|c|c|c|c|c|c|c|c|}
\hline Effect & Parameter & Estimate & s.e. & $\mathrm{df}$ & $t$ & $\mathrm{pr}>t$ & $E_{\text {Std. }}$ \\
\hline \multirow{4}{*}{ Fixed } & Intercept & 1.11220 & 0.0398 & 8 & 27.92 & $<0.0001$ & 0.8 \\
\hline & Ln Dbh & -0.05220 & 0.0098 & 695 & -5.31 & $<0.0001$ & -0.8 \\
\hline & $\mathrm{SDI}^{0.5}$ & -0.00500 & 0.0009 & 695 & -5.39 & $<0.0001$ & -1.1 \\
\hline & SDI $^{0.5} \times$ Pct. conifer BA ${ }^{\mathrm{a}}$ & -0.00146 & 0.0005 & 695 & -3.16 & 0.0017 & -0.6 \\
\hline \multirow{2}{*}{ Random } & Site $(n=9)$ & 0.00452 & 0.0025 & & & & \\
\hline & Residual & 0.01546 & 0.0008 & & & & \\
\hline
\end{tabular}

${ }^{\mathrm{a}}$ Percent conifer BA (arcsine transformed $)=\operatorname{Sin}^{-1}\left((0.01 * \text { percent conifer BA })^{0.5}\right)$. 


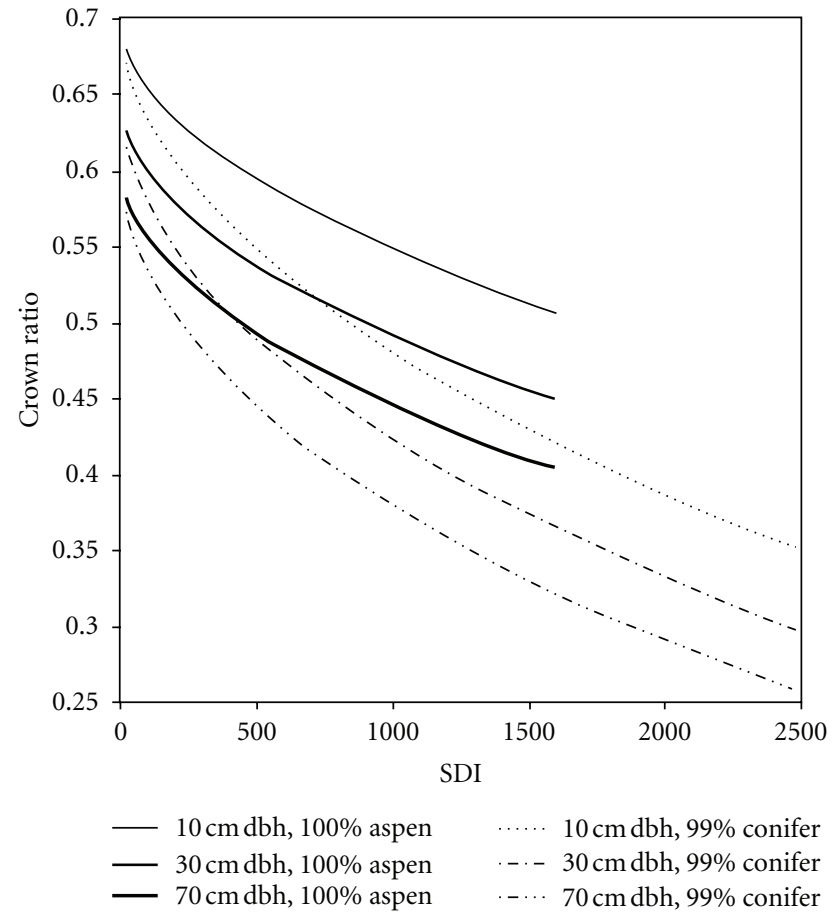

Figure 2: Relationship between aspen crown ratio, stand density index (SDI), tree size, and percent conifer in terms of BA, among aspen stems $(n=707)$ in nine stands around the Lake Tahoe Basin.

with $50 \%$ conifer composition, the same increase in SDI results in CR decreasing 13\% (from 0.51 to 0.45 ) (Figure 2). When the stand-level succession index was tested as a fixed effect, a significant interaction between vicinity SDI and succession index $(\mathrm{df}=8, P=0.03)$ was detected. This indicated that aspen in dense patches within each stand maintained longer live crowns in stands with lower overall succession to conifer.

\section{Discussion}

For any level of stand density, aspen stem BA growth was slower with a greater proportion of conifer neighbors (Figure 1). Since fir trees carry more leaf area than pines for a given tree size [27] they cast more shade, yet they did not exhibit significantly greater competition. This finding suggests that pines (that cast less shade) may exert greater belowground competition, or that pines were more common in areas less suited to aspen growth. The analysis of species composition highlighted limitations of the sampling protocol: (i) too few data were available to test for the effects of less common species groups (hardwoods, juniper); (ii) combining conifer species into pine and fir groups in prism plot BA tallies prevented us from examining competitive effects of individual species. However, in general, our findings were consistent with studies from other regions, where conifers were impacting aspen growth $[1,3,9]$.

Our finding that aspen growth was 20-25\% faster on the southern and western sides of Lake Tahoe Basin coincides with records of annual precipitation which were approximately double on the southern and western sides of the lake as that on the eastern side [28]. The deeper snowpack in the south and west takes longer to melt and postpones the initiation of leaf emergence and growth in spring. However, it is likely that the greater snowpack supports prolonged growth through the season by making more soil moisture available and creating or sustaining mesic soil moisture conditions that favor aspen growth [22].

The BA increment model predicts that aspen growth peaks and then declines as stems become larger (Figure 1). At higher elevations, peak growth was less, and it occurred at smaller tree sizes. These results suggest that, in general, aspen stems of a given size are older at higher elevations, and that aspen trees at higher elevations cannot become as large as aspen near lake level. However, our data represent the average of only five growing seasons (2006-2010). The effects and interactions between factors influencing aspen growth may change over time. For instance, slower growth measured on the drier eastern side of Lake Tahoe suggests that growth may decrease basin-wide if precipitation declines in future; or, that future growth at mid-elevations surpasses growth at lake level, where rising temperature and declining water availability could impact aspen growth $[22,29,30]$. We advise caution when interpreting results obtained by applying the aspen BAI and CR models in combination to generate estimates of growth under different conifer succession or removal scenarios. Until the models are validated with independent data for a range of management and climatic conditions, the expected values should only be regarded as indicative estimates.

The random effect coefficient for differences in growth between stands (0.037) was small relative to the residual variance $(0.233)$ (Table 3$)$. We cautiously infer that only minor differences in growth between stands-presumably each representing different clones-were observed after controlling for the fixed effects (location, tree and crown size, stand density, and conifer composition). Errors associated with estimates of BA growth obtained from ring measurements certainly contributed to residual variance. Inflated residual variance might obscure a genetic variance component. Similarly, the relatively small random effect coefficient for differences in CR between stands suggested that crown rise was mainly under environmental (as opposed to genetic) control within the nine 1-ha sample stands (Table 5). Individual sample stands were each assumed to represent nine different clones, yet the sample stands could have comprised more than one clone [31].

At Lake Tahoe, aspen CR averaged 0.48 but was highly variable (0.15-0.89; Table 4). In multispecies and multilayered stands of southeastern British Columbia, aspen CR was equally variable, but much lower on average $(0.32$; [32]). The nine stands sampled for CR at Lake Tahoe were mixed, multiaged aspen-conifer stands. In the absence of major disturbance, young stems were ascending to upper canopy status in partial shade and had lost live crown in the process. For example, a $10-\mathrm{cm}$ dbh aspen was predicted to have CR 0.7 with zero neighbors within an 8-m radius. Larger aspen in the same situation had lower CRs, contradicting trends depicted by an aspen CR model for the Lake States, where 
the author concluded that larger diameter aspen had higher $\mathrm{CR}$, because they were usually dominant and codominant, whereas smaller trees were suppressed [33]. Our CR model for the mixed multiaged stands at Lake Tahoe indicated that smaller aspen trees had longer crowns that would retreat with advancing size. When neighbor trees were present, their combined SDI impacted aspen CR; CR was further impacted as the proportion of neighbors that were conifer increased. This finding supports timely removal of conifer to reduce crowding and postpone crown recession in aspen, provided that care is taken to protect aspen from damage that we found correlated with lower CR.

Our "static" CR equation is not ideal for predicting crown rise over time [34], but it does suggest that conifers were inciting crown recession among aspen. Loss of live crown leads to loss of vigor, with an associated decline in pest and disease resistance. In a clonal species such as aspen, loss of crown volume and vigor among existing stems will lessen carbohydrate storage within root systems $[35,36]$. The significant interaction between local crowding (vicinity SDI) and the progression of succession to conifer at the stand level (succession index) indicated that aspen trees in dense patches within each stand maintained longer live crowns in stands with lower overall succession to conifer. This finding supports a clonal resource-sharing hypothesis: healthy aspen clones with few conifers are able to divert resources to stems in crowded patches, enabling them to maintain longer live crowns.

When examined collectively, our findings indicated that stand density and the presence of conifer neighbors both contributed to the loss of live crown, which in turn correlated strongly with decline in aspen BA increment. Evidence that conifers impacted aspen growth independent of CR, and impacted CR independent of stand density, suggested that conifers were inciting a cascading decline in aspen. Declining growth and vigor among aspen stems around the Lake Tahoe Basin will lessen recruitment of stems to the largest diameter classes that provide habitat and aesthetic values and could ultimately result in loss of aspen stands and associated standand landscape-scale biodiversity. Sustaining aspen's presence around the Lake Tahoe Basin, without reintroducing fire to the system or clearing new areas for aspen to colonize, will require some management intervention to relieve crowding and promote regeneration. Our results support application of conifer removal and stand density control in aspen-conifer stands at Lake Tahoe to enhance aspen growth and vigor.

\section{Acknowledgments}

The authors sincerely thank their collaborators Stephanie Coppeto and Victor Lyon (USDA Forest Service), David Catalano (Nevada Division of Wildlife), Tamara Sasaki and Silver Hartman (California State Parks), and Judy Clot (California Tahoe Conservancy). Field assistance was provided by Chris Harrison, Jesse Jeffress, Nick Knipe, Brandon Namm, Kirk Perttu, Dustin Revel, and Chris Valness. Aidan Stephens aged increment cores. Jeffrey Kane, Phillip van Mantgem, and anonymous reviewers provided valuable comments on an earlier version of the paper. This research was supported using funds provided by the Bureau of Land Management through the sale of public lands as authorized by the Southern Nevada Public Land Management Act.

\section{References}

[1] W. D. Shepperd, D. L. Bartos, and S. A. Mata, "Above- and below-ground effects of aspen clonal regeneration and succession to conifers," Canadian Journal of Forest Research, vol. 31, no. 5, pp. 739-745, 2001.

[2] T. G. Wall, R. F. Miller, and T. J. Svejcar, "Juniper encroachment into aspen in the northwest Great Basin," Journal of Range Management, vol. 54, no. 6, pp. 691-698, 2001.

[3] A. L. Gallant, A. J. Hansen, J. S. Councilman, D. K. Monte, and D. W. Betz, "Vegetation dynamics under fire exclusion and logging in a Rocky Mountain watershed, 1856-1996," Ecological Applications, vol. 13, no. 2, pp. 385-403, 2003.

[4] A. P. Di Orio, R. Callas, and R. J. Schaefer, "Forty-eight year decline and fragmentation of aspen (Populus tremuloides) in the South Warner Mountains of California," Forest Ecology and Management, vol. 206, no. 1-3, pp. 307-313, 2005.

[5] B. E. Jones, T. H. Rickman, A. Vazquez, Y. Sado, and K. W. Tate, "Removal of encroaching conifers to regenerate degraded aspen stands in the Sierra Nevada," Restoration Ecology, vol. 13, no. 2, pp. 373-379, 2005.

[6] M. W. Kaye, D. Binkley, and T. J. Stohlgren, "Effects of conifers and elk browsing on quaking aspen forests in the central Rocky Mountains, USA," Ecological Applications, vol. 15, no. 4, pp. 1284-1295, 2005.

[7] A. E. Smith and F. W. Smith, "Twenty-year change in aspen dominance in pure aspen and mixed aspen/conifer stands on the Uncompahgre Plateau, Colorado, USA," Forest Ecology and Management, vol. 213, no. 1-3, pp. 338-348, 2005.

[8] J. D. Bates, R. F. Miller, and K. W. Davies, "Restoration of quaking aspen woodlands invaded by western juniper," Rangeland Ecology and Management, vol. 59, no. 1, pp. 88-97, 2006.

[9] W. J. Calder, K. J. Horn, and S. B. St. Clair, "Conifer expansion reduces the competitive ability and herbivore defense of aspen by modifying light environment and soil chemistry," Tree Physiology, vol. 31, no. 6, pp. 582-591, 2011.

[10] D. A. Perala, "Quaking aspen (Populus tremuloides Michx.)," in Silvics of North America, I. I. Deciduous, R. M. Burns, and B. H. Honkala, Eds., no. 654, pp. 555-569, United States Department of Agriculture Handbook, 1990.

[11] B. V. Barnes, "The clonal growth habit of American aspens," Ecology, vol. 47, pp. 439-447, 1966.

[12] D. L. Bartos, "Landscape dynamics of aspen and conifer forests," in Sustaining Aspen in Western Landscapes: Symposium Proceedings, W. D. Shepperd, D. Binkley, D. L. Bartos, T. J. Stohlgren, and L. G. Eskew, Eds., pp. 5-14, U.S. Department of Agriculture, Forest Service, Rocky Mountain Forest and Range Experiment Station, RMRS-P-18, Grand Junction, Colo, USA, 2001.

[13] W. D. Shepperd, P. C. Rogers, D. Burton, and D. Bartos, "Ecology, biodiversity, management, and restoration of aspen in the Sierra Nevada," U.S. Department of Agriculture, Forest Service, Rocky Mountain Forest and Range Experiment Station, RMRS-GTR-178, Fort Collins, Colo, USA, 2006.

[14] T. J. Stohlgren, D. Binkley, G. W. Chong et al., "Exotic plant species invade hot spots of native plant diversity," Ecological Monographs, vol. 69, no. 1, pp. 25-46, 1999.

[15] T. J. Kuhn, H. D. Safford, B. E. Jones, and K. W. Tate, "Aspen (Populus tremuloides) stands and their contribution to plant 
diversity in a semiarid coniferous landscape," Plant Ecology, vol. 212, no. 9, pp. 1451-1463, 2011.

[16] T. W. Richardson and S. K. Heath, "Effects of conifers on aspen-breeding bird communities in the Sierra Nevada," Transactions of the Western Section of the Wildlife Society, vol. 40, pp. 68-81, 2004.

[17] D. L. Bartos and R. B. Campbell, "Decline of quaking aspen in the interior west-examples from Utah," Rangelands, vol. 20, no. 1, pp. 17-24, 1998.

[18] D. Binkley, "Age distribution of aspen in Rocky Mountain National Park, USA," Forest Ecology and Management, vol. 255, no. 3-4, pp. 797-802, 2008.

[19] G. E. Dixon, "Essential FVS: a user's guide to the forest vegetation simulator (Revised 2011)," Internal Report, U.S. Department of Agriculture, Forest Service, Forest Management Service Center, Fort Collins, Colo, USA, 2002.

[20] C. E. Keyser and G. E. Dixon, "Western Sierra Nevada (WS) variant overview-forest vegetation simulator (Revised 2011)," Internal Report, U.S. Department of Agriculture, Forest Service, Forest Management Service Center, Fort Collins, Colo, USA, 2008.

[21] R. Boone, J. Tardif, and R. Westwood, "Radial growth of oak and aspen near a coal-fired station, Manitoba, Canada," TreeRing Research, vol. 60, no. 1, pp. 45-58, 2004.

[22] E. H. Hogg, J. P. Brandt, and B. Kochtubajda, "Factors affecting interannual variation in growth of western Canadian aspen forests during 1951-2000," Canadian Journal of Forest Research, vol. 35, no. 3, pp. 610-622, 2005.

[23] SAS Institute Inc, SAS/STAT 9.1 User's Guide, vol. 1-7, SAS Institute Inc, Cary, NC, USA, 2nd edition, 2004.

[24] R. C. Littell, G. A. Milliken, W. W. Stroup, R. D. Wolfinger, and O. Schabenberger, SAS for Mixed Models, SAS Institute Inc, Cary, NC, USA, 2nd edition, 2006.

[25] J. N. Long and T. W. Daniel, "Assessment of growing stock in uneven-aged stands," Western Journal of Applied Forestry, vol. 5, pp. 93-96, 1990.

[26] J. D. Shaw, "Application of stand density index to irregularly structured stands," Western Journal of Applied Forestry, vol. 15, no. 1, pp. 40-42, 2000.

[27] R. F. Gersonde and K. L. O'Hara, “Comparative tree growth efficiency in Sierra Nevada mixed-conifer forests," Forest Ecology and Management, vol. 219, no. 1, pp. 95-108, 2005.

[28] L. Dolislager, A. Lashgari, J. Pederson, and T. VanCuren, "Lake Tahoe Atmospheric Deposition Study (LTADS)," Final Report, Chapter 2: Atmospheric Processes. Staff Report, California Environmental Protection Agency Air Resources Board, Sacramento, Calif, USA, 2006.

[29] E. H. Hogg, J. P. Brandt, and M. Michaelian, "Impacts of a regional drought on the productivity, dieback, and biomass of western Canadian aspen forests," Canadian Journal of Forest Research, vol. 38, no. 6, pp. 1373-1384, 2008.

[30] K. Brown, A. J. Hansen, R. E. Keane, and L. J. Graumlich, "Complex interactions shaping aspen dynamics in the Greater Yellowstone Ecosystem," Landscape Ecology, vol. 21, no. 6, pp. 933-951, 2006.

[31] V. D. Hipkins and J. H. Kitzmiller, "Genetic variation and clonal distribution of quaking aspen in the central Sierra Nevada," Transactions of the Western Section of the Wildlife Society, vol. 40, pp. 32-44, 2004.

[32] H. Temesgen, V. LeMay, and S. J. Mitchell, "Tree crown ratio models for multi-species and multi-layered stands of southeastern British Columbia," Forestry Chronicle, vol. 81, no. 1, pp. 133-141, 2005.
[33] M. R. Holdaway, "Modeling tree crown ratio," Forestry Chronicle, vol. 10, pp. 451-455, 1986.

[34] M. W. Ritchie and D. W. Hann, Equations for predicting height to crown base for fourteen tree species in southwest Oregon, Oregon State University Forest Research Laboratory Research Paper 50, Corvallis, Ore, USA, 1987.

[35] R. K. Tew, "Root carbohydrate reserves in vegetative reproduction of aspen," Forest Science, vol. 16, pp. 318-320, 1970.

[36] N. V. DeByle and R. P. Winokur, Aspen: Ecology and Management in the Western United States, U.S. Department of Agriculture, Forest Service, Rocky Mountain Forest and Range Experiment Station, GTR-RM-119, Fort Collins, Colo, USA, 1985. 

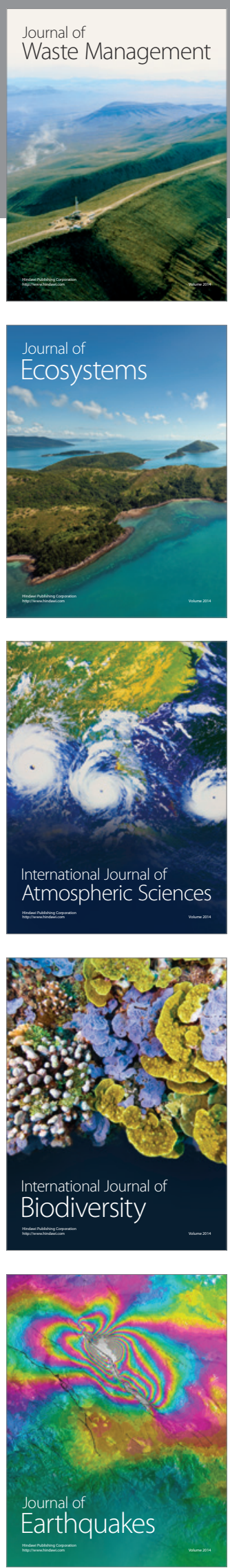
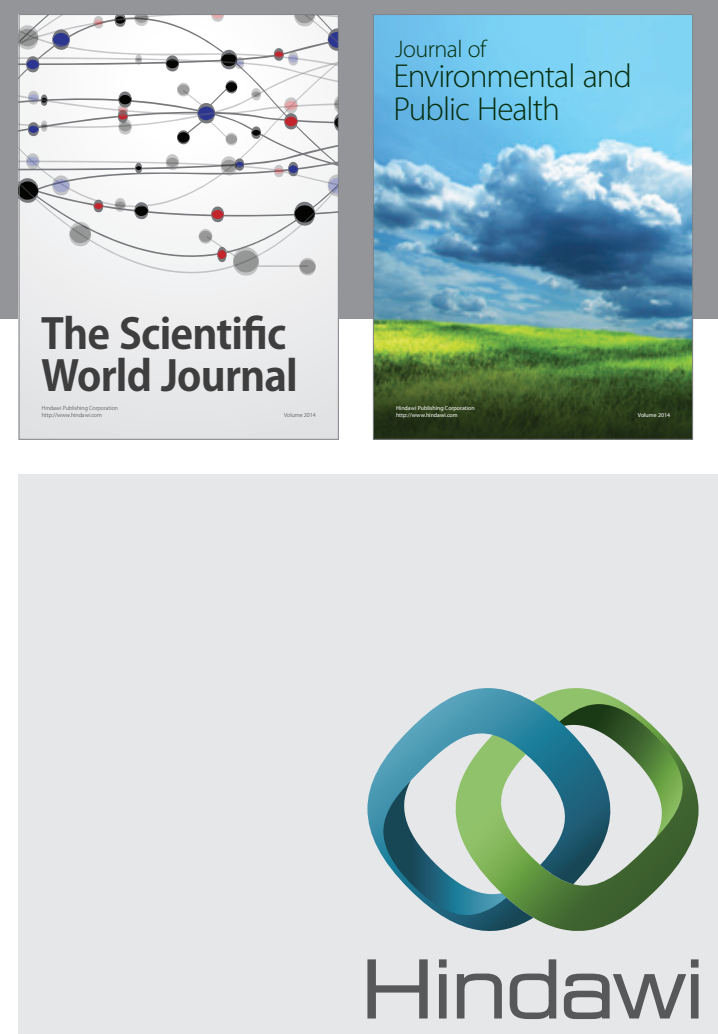

Submit your manuscripts at

http://www.hindawi.com
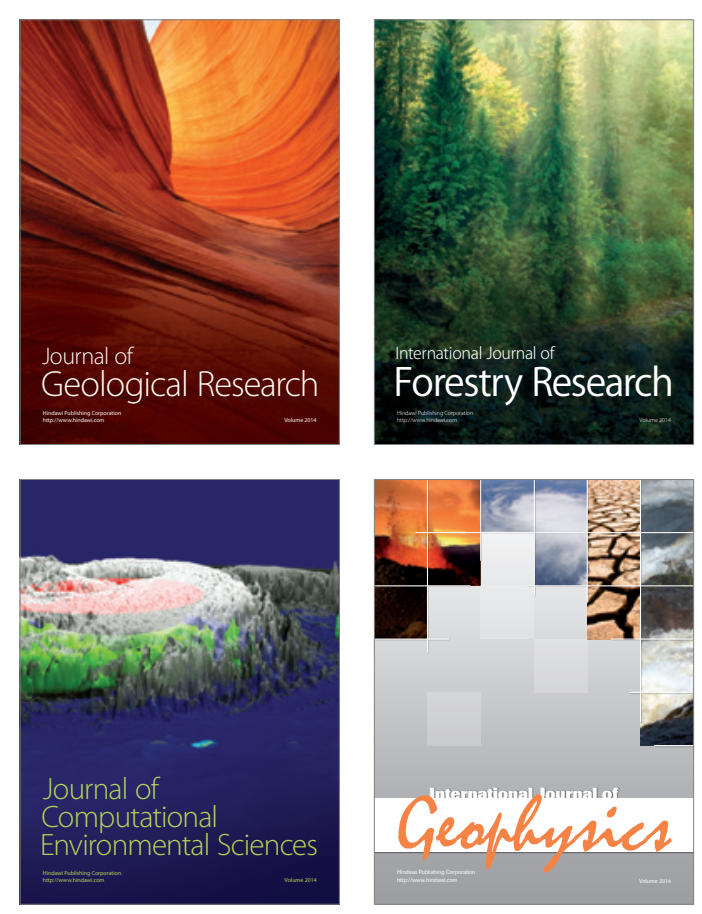
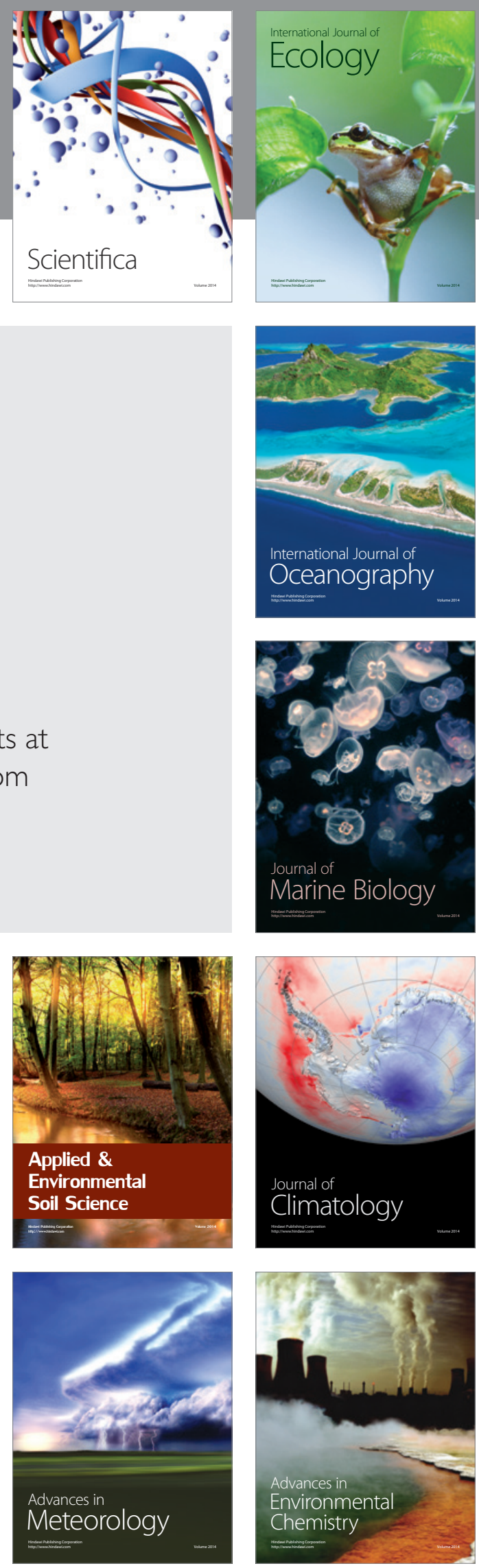